compatible with the results of Brown and Riggilo ${ }^{12}$ with the non-selective drug sotalol. The only published findings that totally disagree with these results are those of Walter et al. ${ }^{15}$ They showed that propranolol had no significant effect on the blood glucose levels after insulin administration. This trial is not strictly comparable, however, since it was performed after a five-day fast, and by this time liver glycogen stores, a readily available source of glucose, would have been exhausted. Abramson et $a l^{2}$ partly disagreed with the above results. They found that the initial hypoglycaemic effect of the insulin was not potentiated by propranolol but confirmed that the return to normoglycaemia was significantly delayed.

Both supposedly cardioselective beta-adrenergic receptor blocking agents used in this trial potentiated the initial hypoglycaemic effect of the insulin in the same way as propranolol, but only metoprolol significantly delayed the return to normoglycaemia. There are no other published results on the effect of these two drugs on blood glucose levels and comparison must therefore be made with the only other experiment in which selective beta-adrenergic receptor blockade was used. When Baird and Carter ${ }^{14}$ gave oral practolol and tolamolol to rats these drugs did not significantly potentiate the hypoglycaemic effect of insulin one hour after administration. Only when given intraperitoneally in very high doses did practolol have a possible potentiating effect. Unfortunately, no information was given on the return of blood glucose levels towards normal, but Barnett, ${ }^{16}$ using the same drug in man, did not show any delayed normoglycaemia after insulin. Recently both products have been almost completely withdrawn from clinical practice.

These results were obtained in healthy volunteers and are therefore not strictly applicable to patients with diabetes mellitus. A similar trial in diabetics should therefore be under- taken to determine with certainty the safety of such drugs in the condition.

I thank Dr D Barnett, consultant physician to this hospital, for placing the facilities of his metabolic laboratory at my disposal and for allowing his technician, Mrs Jill Unsworth, to perform the analyses. I am grateful to Geigy Pharmaceuticals Ltd for providing financial assistance and to my 11 volunteers without whose help this project would not have been possible.

\section{References}

1 Hagen, J H, and Hagen, P B, in Actions of Hormones on Molecular Processes, ed G Litwack and D Kritchevsky, p 268. New York, Wiley, 1964.

${ }^{2}$ Kotler, M N, Berman, L, and Rubenstein, A H, Lancet, 1966, 2, 1389.

${ }^{3}$ Mackintosh, T F, Lancet, 1967, 1, 104.

4 Wray, R, and Sutcliffe, S B J, British Medical fournal, 1972, 2, 592.

5 Abramson, E A, Arky, R A, and Woeber, K A, Lancet, 1966, 2, 1386.

${ }^{6}$ Berk, J L, Hagen, J F, and Beyer, W H, Hormone and Metabolic Research, $1970,2,277$.

7 Nickerson, $\mathrm{M}$, in The Pharmacological Basis of Therapeutics, ed L S Goodman and A Gilman, 4th edn, p 569. London, Collier-Macmillan, 1970

${ }^{8}$ Fitzgerald, J D, Diabetologia, 1968, 5, 339.

9 Cowell, J W F, and Hetenyi, G, jun, Archives Internationales de Pharmacodynamie et Therapie, 1969, 178, 412.

10 Ablad, B, et al, Acta Pharmacologica et Toxicologica, 1975, 36, Suppl No 6.

11 Werner, W, Rey, H-G, and Wielinger, H, Analytical Chemistry, 1970, 252, 224.

12 Brown, J H, and Riggilo, D A, Proceedings of the Society for Experimental Biology and Medicine, 1968, 127, 1258.

13 Abramson, E A, and Arky, R A, Diabetes, 1968, 17, 141.

${ }^{14}$ Baird, J R C, and Carter, A J, European fournal of Pharmacology, 1974, 25, 272.

15 Walter, R M, et al, fournal of Clinical Investigation, 1974, 54, 1214.

${ }^{16}$ Barnett, D, 1976, personal communication.

\title{
First electrocardiogram in recent myocardial infarction
}

\author{
J B McGUINNESS， T B BEGG，T SEMPLE
}

British Medical fournal, 1976, 2, 449-451

\section{Summary}

The admission electrocardiogram (ECG) was studied in 898 patients admitted to a coronary care unit over two years. The diagnosis made from this tracing was compared with that made at the end of the patient's stay. About half the cases of recent myocardial infarct were diagnosed from the admission ECG, but accuracy rose to $83 \%$ with serial ECGs in the unit. The ECG is important but not entirely reliable in the early detection of acute myocardial infarction, which should be largely a clinical diagnosis.

\section{Introduction}

Studies of myocardial infarction have shown that mortality is high at and immediately after its onset and rapidly decreases

Department of Cardiology, Victoria Infirmary, Glasgow G42

J B MCGUINNESS, MD, FRCP, consultant physician

T B BEGG, MB, FRCP, consultant physician

T SEMPLE, MD, FRCP, consultant physician with time. ${ }^{12}$ This observation has led to the formation of special units for the early care of these patients, and in some centres these have been logically extended to the patient's home as mobile coronary care units.

Implicit in this is the assumption that the condition can be diagnosed in the early stages, and many clinicians and even laymen believe that the value of the electrocardiogram (ECG) is paramount. The value of an early ECG has not yet been clearly defined, but its diagnostic limitations in a selected group of patients with mild myocardial infarction have been shown. ${ }^{3}$

We decided to study prospectively over two years every patient with suspected myocardial infarction admitted to a coronary care unit to assess the relation between the admission ECG diagnosis of acute myocardial infarction and the eventual diagnosis reached after clinical appraisal, serial ECGs, and enzyme studies, with necropsy findings when appropriate.

\section{Patients and methods}

Over two years 918 patients were admitted to a coronary care unit. As a rule only patients thought by their practitioners to have had a myocardial infarction within the previous 48 hours were admitted but there were no age or sex restrictions. An occasional exception was made to this rule for troublesome complications of an older myocardial infarct such as arrhythmia. A full 12-lead ECG was recorded on admission in 898 patients and on each successive morning until the patient left the monitoring unit. These 898 patients are the subjects of the 
present study. Blood was removed for estimating serum creatine phosphokinase, aspartate aminotransferase, and alanine aminotransferase on admission and on the morning of the second and third day in every patient.

Seven interpretations of the admission ECG were available to the physician in charge of the unit: definite, probable, or doubtful recent infarction, each with or without $Q$ waves, and also no recent infarction.

Surviving patients remained in the coronary care unit for 72 hours, or longer if they developed a complication. At the end of their stay serial ECG tracings were studied together and a revised interpretation was noted. Finally a complete and comprehensive diagnosis was made using World Health Organisation criteria, ${ }^{2}$ taking into account the clinical history and progress, the serial ECG interpretation, and results of the serum enzyme studies.

When an earlier ECG of a patient later became available the initial interpretation stood as the admission ECG diagnosis but this interpretation was reviewed in the light of the previous tracing when making the serial ECG diagnosis and the final comprehensive diagnosis.

Thus diagnoses were available from $(a)$ the admission ECG (b) the admission ECG in the light of a previous ECG when available; (c) ECGs recorded during and even before the stay in the unit (seria ECG diagnosis); and (d) all ECGs as in (c) with any additional diagnostic information such as history, clinical course, enzyme studies, and necropsy information when appropriate (final comprehensive diagnosis).

All observations were recorded on a special computerised case sheet, the information being transferred later to tape and processed by a PDP 12 computer.

\section{Results}

Of the 898 patients studied, 400 had a definite myocardial infarct diagnosed at the end of their stay in the coronary care unit using all the available information, and another 49 died before adequate serial studies could be made. In all 449 patients with a final comprehensive diagnosis of recent myocardial infarct the diagnosis interpreted from the admission ECG had been: definite myocardial infarct in $229(51 \%)$; probable myocardial infarct in $120(27 \%)$; doubtful myocardial infarct in $30(7 \%)$; and no myocardial infarct in 70 $(16 \%)$.

Of the 400 survivors with a final comprehensive diagnosis of definite myocardial infarct, $334(84 \%)$ had had a serial ECG diagnosis of definite recent myocardial infarct. When this positive serial ECG diagnosis was compared with the interpretation of the single admission ECG $195(49 \%)$ had been considered to have a definite myocardial infarct, $77(19 \%)$ a probable myocardial infarct, $19(5 \%)$ a doubtful myocardial infarct, and $43(11 \%)$ no myocardial infarct.

The time between onset of symptoms and admission to the unit was examined in all 449 patients with infarction to determine the relation between the time of admission and the diagnostic value of the first ECG. This information was absent in six patients but the results in the remaining 443 are shown in the table. The median time of admission from the onset of symptoms was 4.66 hours.

A past ECG became available after the interpretation of the admission tracing in 129 of the 449 patients with a final comprehensive diagnosis of myocardial infarct, and 29 of these $(23 \%)$. already showed an infarct pattern in the same zone that might have called for a revision of the admission ECG interpretation. Indeed, had the admission ECG fresh infarct interpretation been reversed in these the number of definitive positive admission tracings would have been reduced from $229(51 \%)$ to $200(45 \%)$

Of the 400 survivors of infarcts pathological $Q$ waves were present in the admission ECG in 243 but absent in the discharge tracing in $40(17 \%)$ of these. The remaining 157 patients had no $Q$ waves on their admission ECGs, but $73(47 \%)$ of these had a pathological $Q$ wave by the end of their stay in the unit.

In these patients with a confirmed infarct mortality fell from $24.5 \%$ in those who were thought from their admission ECG to have a definite myocardial infarct, to $22.9 \%$ in those with a probable infarct, to $13.2 \%$ and $12.5 \%$, respectively, in the groups with doubtful or no infarct on the admission ECG.

\section{Discussion}

There is a widespread tendency to accept the ECG as a reliable indicator of the presence or absence of acute myocardial infarction. This bland acceptance has been questioned by Short, ${ }^{3}$ who showed that only $18 \%$ of 142 patients who had $\frac{\bar{\sigma}}{\bar{\rho}}$ suffered 150 episodes of acute myocardial infarction seen within $\frac{\omega}{\vec{T}}$ 48 hours of the incident and mild enough to be treated at home $\stackrel{\mathbb{Q}}{\varnothing}$ had an ECG diagnostic of myocardial infarct when first seen, and $27 \%$ had no abnormality at all. If patients are to be treated $\vec{\circ}$ as soon as possible after the incident the limitations of the ECG in making an early diagnosis should be understood.

Our group included patients of all ages and both sexes with myocardial infarcts of all grades of severity from mild to massive. Most were seen early in the incident, the median time of admis- iv sion being 4.66 hours from the onset of symptoms.

The figures which emerge show that, of those with definite myocardial infarct according to the evidence available over several days, only $51 \%$ could have been diagnosed with any $\vec{c}$ degree of certainty from the first ECG. A further $27 \%$ were 음 considered to have probable myocardial infarcts in the light of $\mathrm{N}$ the first tracing, while $16 \%$ had ECGs considered to show nothing even suggestive of a recent myocardial infarct. In other words, by relying entirely on the first ECG, about half the patients suffering from myocardial infarct might have been missed and, even accepting the "probables," almost a quarter $\vec{\theta}$ of the patients would have been missed, thus illustrating the potential danger of depending for early diagnosis on an ECG, even when interpreted by an experienced observer. In the mild and doubtful group, where most aid is needed, the single ECG is of least value.

When the diagnostic value of the first ECG is considered in relation to the delay between onset of symptoms and admission, only those admitted within one hour and those admitted between two and seven days stand out (see table). It is our impression that patients admitted very early tend to have severe symptoms and a higher porportion of diagnostic injury patterns. In those admitted late the ECG can be expected to have greater diagnostic precision.

Serial ECGs of the 400 survivors with a final comprehensive diagnosis of myocardial infarct were interpreted on their own. Three hundred and thirty-four $(83 \%)$ indicated definite infarct, 응 but only $195(49 \%)$ of the admission ECGs had been considered $३$ diagnostic, and $43(11 \%)$ had shown no significant abnormal 을 changes. These findings confirm that the ECG becomes pro- No gressively more helpful as time goes on and that serial ECGs are vital in overall assessment. This agrees with our knowledge of the behaviour of myocardial infarcts, in that they may continue to spread into the surrounding ischaemic zone for up to a week.

Interpretation of a past ECG tracing in 129 patients showed C infarction already present in the same zone in 29 patients. This raises an interesting practical point about whether the general practitioner should be sent a copy of the latest hospital ECG as a baseline for future comparison.

Another rather surprising finding in the 400 surviving $\frac{T}{0}$ patients was the behaviour of $\mathrm{Q}$ waves, often regarded as per- $\frac{\vec{D}}{\mathbb{D}}$ manent features of an ECG, once they are present. Of those $\frac{\Upsilon}{\square}$ presenting with pathological $Q$ waves $17 \%$ had lost them by the

Time between onset of symptoms and admission related to frequency of diagnosis of myocardial infarction on first ECG.

\begin{tabular}{|c|c|c|c|c|c|c|c|c|c|c|}
\hline Delay (hours): & $<1$ & -2 & -4 & -8 & -12 & -24 & -48 & -7 days & $>7$ days & Total \\
\hline $\begin{array}{l}\text { No of patients } \\
\text { No }(\%) \text { of patients with } \\
\text { positive ECG } \ldots\end{array}$ & $\begin{array}{c}15 \\
9(60)\end{array}$ & $\begin{array}{c}65 \\
31(48)\end{array}$ & $\begin{array}{c}122 \\
66(54)\end{array}$ & $\begin{array}{c}92 \\
48(52)\end{array}$ & $\begin{array}{c}52 \\
22(42)\end{array}$ & $\begin{array}{c}44 \\
22(50)\end{array}$ & $\begin{array}{c}30 \\
15(50)\end{array}$ & $\begin{array}{c}19 \\
13(68)\end{array}$ & $\begin{array}{c}4 \\
1(25)\end{array}$ & $\begin{array}{c}443 \\
227(51)\end{array}$ \\
\hline
\end{tabular}


time they were discharged. Less surprising was the finding that of those presenting without $Q$ waves $47 \%$ developed them while in the unit.

When mortality was related to the appearance of the admission ECG those regarded as showing a definite myocardial infarct had the highest mortality $(24.5 \%)$. More surprising and even disturbing was a death rate of $13.2 \%$ in those regarded as having doubtful myocardial infarct and of $12.5 \%$ in those showing no infarct.

Thus, of patients admitted to this coronary care unit because of suspected myocardial infarction, about half were suffering from this condition. Of this group $51 \%$ showed evidence of a recent myocardial infarct on the first ECG, with a further $27 \%$ in the probable group. The earlier an ECG is taken in a suspected case, especially if mild, the greater is the chance it will mislead the clinician, but as time goes on the tracings, and especially serial studies, become more reliable.
The ECG must be regarded as an important but not totally reliable diagnostic tool. Recent myocardial infarction is largely a clinical diagnosis helped by ECG or serial enzymes studies, or both.

We thank Miss $\mathrm{K} \mathrm{A}$ Scott and the nursing staff of the coronary care unit, Miss $M$ Jordan of the bioengineering department, Strathclyde University, for her help in data collection and analysis, and Miss M H Gibson for secretarial help.

\section{References}

${ }^{1}$ McNeilly, R H, and Pemberton, J, British Medical fournal, 1968, 3, 139. 2 World Health Organisation, Ischaemic Heart Disease Registers: Report of the Fifth Working Group, p 31. Copenhagen, WHO, Regional Office for Europe, 1971.

${ }^{3}$ Short, D, British Heart fournal, 1970, 32, 6.

\title{
The elderly in a coronary unit
}

\author{
B O WILliaMS, T B BEGG, T SEMPLE, J B McGUINNESS
}

British Medical fournal, 1976, 2, 451-453

\section{Summary}

The clinical features of myocardial infarction were compared in 104 patients over the age of 70 and 399 younger patients admitted to a coronary care unit. Absence of an age bar at 70 years has increased the number of admissions to the unit by $24 \%$, and the number of patients with proved infarcts by $26 \%$. Severe complications are more common and mortality is doubled in the elderly. Although immediate management of primary ventricular fibrillation is as successful in older as in younger patients, treatment of the elderly with less dramatic conditions is less successful. The elderly survivors tend to spend longer in the coronary unit and subsequently in the general medical ward.

\section{Introduction}

Clinical manifestations of heart attacks are considered to be more variable and atypical in elderly patients, and the concept of silent myocardial infarction is widely recognised. ${ }^{1}$ Since the establishment of coronary care units much information has

\footnotetext{
Department of Cardiology, Victoria Infirmary, Glasgow G42 9TY B O WILLIAMS, MB, MRCP, medical registrar (now locum consultant in geriatric medicine)

T B BEGG, MB, FRCP, consultant physician

$T$ SEMPLE, MD, FRCP, consultant physician

J B MCGUINNESS, MD, FRCP, consultant physician
}

been gathered about hospital care of patients with myocardial infarction, but little has been published about the condition in elderly patients, as coronary units have often set an age limit at 69 years because it was thought they could not cope with all age groups. ${ }^{2}$ We compare here aspects of the admission, progress, and complications in patients above and below the age of 70 years suffering from acute myocardial infarction treated in the coronary care unit of the Victoria Infirmary, Glasgow.

\section{Patients and methods}

Over two years 918 patients were admitted to the unit with suspected myocardial infarction. Symptoms had begun within the previous 48 hours in all but a few cases. Seven hundred and forty patients were under the age of 70 years, and 178 were 70 years or older. We studied the 503 patients with confirmed acute myocardial infarction. World Health Organisation criteria ${ }^{3}$ were used to establish the diagnosis.

Patients with proved myocardial infarction were treated in the unit for at least 72 hours. All had an intravenous infusion throughout their stay, and heparin was administered in this infusion for the first 36 hours unless contraindicated. Continuous electrocardiographic monitoring was carried out using central display and alarm signals. Complications were treated conventionally and facilities for immediate defibrillation were available. On discharge from the monitoring unit survivors were transferred to other wards in the medical division.

All patients with suspected myocardial infarction were graded for severity on admission according to the Peel coronary prognostic index, and on transfer out of the unit by a simplified three-grade system. Case records, specially prepared for computer study, were kept for all patients.

\section{Results}

Table I shows the age and sex distribution of all 503 patients. The peak incidence was in men aged 60 to 64 years and in women

TABLE I-Age and sex distribution of 503 patients with confirmed myocardial infarction

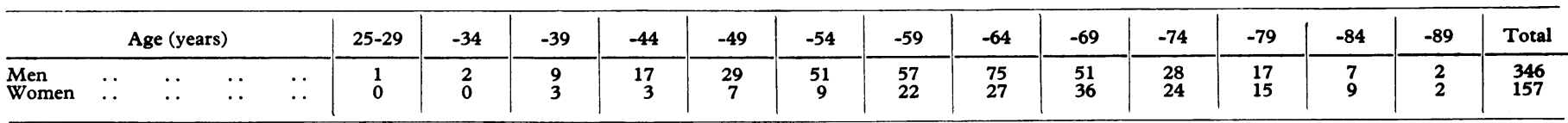

